\title{
QUANTIFICAÇÃO DE MANIFESTAÇÕES PATOLÓGICAS EM CONCRETO ARMADO, METODOLOGIA GDE/UNB - ESTUDO DE CASO
}

\author{
REIS, TÁSSIO \\ Estudante \\ Faculdade Área1 \\ Bahia; Brasil \\ tassio.carvalho10@hotmail.com
}

\author{
RIVETTI, MARIANNA \\ Professora \\ Faculdade Área1 \\ Bahia; Brasil \\ marianna.rivetti@area1.edu.br
}

\section{RESUMO}

Em cidades como Salvador, de alta agressividade ambiental é necessário observar o comportamento da estrutura com mais atenção, pois por ser um ambiente litorâneo as estruturas estão mais expostas à agentes agressores. Manifestação patológica é a ciência que estuda as doenças, que diminuem o desempenho e vida útil da estrutura. Até em construções mais recentes é possível que se encontre problemas mais sérios. Quantificar o nível de degradação é interessante para priorizar as intervenções que devem ser realizadas. O intuito foi apresentar, avaliar e quantificar manifestações patológicas nas garagens de um prédio com cerca de 10 anos, localizado em Salvador, usando a metodologia GDE/UnB e apresentar nos resultados os pontos que necessitam de maior prioridade. Pôde-se concluir que até as estruturas mais novas necessitam de cuidados especiais. Durante a visita técnica ao prédio e segundo relatos de moradores, as manifestações patológicas vieram a aparecer após uma reforma feita em uma das lajes, onde provavelmente se danificou a manta de impermeabilização, os resultados demonstram que a maior variabilidade de manifestações patológicas por metro quadrado está justamente na laje onde houve a reforma e que as manifestações patológicas estão se espalhando por toda a estrutura.

Palavras-chave: Concreto Armado, Agressividade ambiental, Metodologia GDE/UnB.

\section{ABSTRACT}

In cities like Salvador, with high environmental aggressiveness, it is necessary to observe the behavior of the structure with more attention, as it is a coastal environment and the structures are more exposed to aggressive agents. Pathological manifestation is the science that studies diseases, which decrease the performance and useful life of the structure. Even in more recent constructions it is possible to encounter more serious problems. Quantifying the level of degradation is interesting to prioritize the interventions that must be carried out. The aim was to present, evaluate and quantify pathological manifestations in the garages of a building with about 10 years old, located in Salvador, using the GDE / UnB methodology and present in the results the points that need the highest priority. It was concluded that even the newest structures need special care. During the technical visit to the building and according to reports from residents, the pathological manifestations came to appear after a renovation made in one of the slabs, where the waterproofing mat was probably damaged, the results show that the greatest variability of pathological manifestations per square meter is precisely on the slab where the renovation took place and that pathological manifestations are spreading throughout the structure.

Key words: Reinforced Concrete, Environmental aggressiveness, GDE / UnB Methodology.

\section{INTRODUÇÃO}

É significativamente crescente nos últimos anos o número de edificações com estrutura de concreto armado que apresentam deterioração precoce, com danos de diversas origens. Dentre essas, destaca-se a ausência quase absoluta de programas de manutenção preventiva das estruturas. São vários os fatores que levam a isto, podendo-se destacar a cultura deficiente relativa à necessidade de manutenção e o conceito errôneo de que as estruturas de concreto eram previstas para durar ilimitadamente, dispensando manutenção. A constatação que as estruturas de concreto, mesmo as bem projetadas e executadas de forma adequada estão sujeitas à ocorrência de deteriorações inesperadas, ocasionando então a busca de aprofundamento dos conceitos de durabilidade e vida útil (CASTRO, 1994).

Diante disso, este artigo teve o objetivo de por um estudo de caso, avaliar de forma quantitativa os danos provocados em uma edificação de concreto armado pela metodologia GDE/UnB, buscando avaliar as principais manifestações 
patológicas existentes nestes elementos. Desta forma, o estudo indicou o estado dos elementos de concreto armado, bem como as manifestações associadas ao mesmo, contribuindo para o entendimento da degradação existente e auxiliando nas tomadas de decisões associadas a manutenção corretiva, bem como preventiva.

2.

\section{REVISÃO DE LITERATURA}

\subsection{Mecanismos de transporte}

Os mecanismos de transporte estão relacionados com a entrada de agentes agressores, causando danos tanto ao concreto quanto à armadura. Os principais mecanismos de transportes são: permeabilidade, absorção capilar, difusão e migração iônica.

- Permeabilidade: Segundo Fusco (2008), essa permeabilidade é condicionada essencialmente pelo fator água/cimento, pelas condições de adensamento do concreto e pela cura realizada após a concretagem. Na fabricação do concreto é necessário uma preocupação especial na escolha dos agregados graúdos, pois quanto mais adequados eles forem, melhor será a qualidade do concreto, pois terá um melhor envolvimento entre o ligante e o agregado graúdo, proporcionando coesão e como produto teremos um concreto menos poroso e permeável, além de se garantir um bom acabamento da peça (CARVALHO e FILHO, 2014).

- Absorção capilar: Permeabilidade e o movimento da água através do concreto são dois mecanismos distintos, sendo, no entanto, influenciados ambos por características como dimensão, distribuição e continuidade dos poros. A absorção capilar depende da finura do cimento (diminui quando a finura aumenta), da relação águacimento (aumenta quando A/C aumenta) e da compacidade do concreto (VILASBOAS, 2003).

- A difusão é o processo de transporte de substâncias de um meio para outro devido a uma diferença de potencial químico, muitas vezes de concentração. Esse fenômeno ocorre tanto para substâncias presentes em meio líquido como para aquelas em meio gasoso. Os dois principais agentes agressivos que comprometem as armaduras de concreto, íons cloreto e o dióxido de carbono $\left(\mathrm{CO}_{2}\right)$ têm a sua penetração controlada por esse fenômeno (RIBEIRO et al., 2014).

- De acordo com (RIBEIRO et al., 2014), a migração iônica é o processo de transporte que ocorre quando existe um potencial elétrico que possibilita o deslocamento dos íons presentes para que se neutralize o efeito da diferença de potencial.

\subsection{Corrosão da armadura}

A corrosão pode ser definida como um processo de deterioração do material devido à ação química ou eletroquímica do meio ambiente, resultando em perda de massa do material (RIBEIRO et al, 2014). A formação de produtos de corrosão que apresentam volume muito superior ao ferro metálico $(\mathrm{Fe})$ causam pressões, gerando fissuras e diminuindo, assim, a aderência entre barra de aço e o concreto, podendo também ocorrer lascamento e destacamento do concreto (BAROGHEL-BOUNY et al., 2014).

No caso da corrosão das armaduras em concreto armado, as formas mais comuns são a corrosão generalizada irregular e a corrosão puntiforme. O primeiro caso está relacionado à corrosão desencadeada pela carbonatação do concreto, que desencadeia a corrosão ao longo de uma superfície extensa do metal. O segundo caso está relacionado à corrosão gerada pela ação dos íons cloreto, com ação localizada em relação à ruptura da película passivadora do aço (FIGUEIREDO e MEIRA, 2013).

\subsubsection{Agressividade do Ambiente e parâmetros de durabilidade}

A NBR 6118 (2014) classifica o ambiente de acordo com a agressividade conforme Tabela 1.

\begin{tabular}{|c|c|c|c|}
\hline $\begin{array}{c}\text { Classe de agressividade } \\
\text { ambiental }\end{array}$ & Agressividade & $\begin{array}{c}\text { Classificação geral do tipo de ambiente } \\
\text { para efeito de projeto }\end{array}$ & $\begin{array}{c}\text { Risco de deterioração } \\
\text { da estrutura }\end{array}$ \\
\hline I & Fraca & Rural / Submersa & Insignificante \\
\hline II & Moderada & Urbana & Pequeno \\
\hline III & Forte & Marinha / Industrial & Elevado \\
\hline IV & Muito forte & Industrial / Respigos de maré & \\
\hline
\end{tabular}

Tabela 1 - Classes de agressividade ambiental conforme NBR 6118. Fonte: NBR 6118, 2014. 
A partir dessa classificação quanto ao meio é possível definir parâmetros especiais, tais como a relação água/cimento, a classe do concreto, o cobrimento nominal, a abertura máxima de fissuras para a estrutura de concreto em ambiente marinho, as condições especiais de exposição, o teor de sulfatos e de cloretos (SILVA, 2017).

Outro ponto importante a ser considerado segundo a NBR 6118, 2014 é o cobrimento mínimo do concreto, este parâmetro leva em consideração o tipo de estrutura, o elemento estrutural a ser concretado e a classe de agressividade, conforme Tabela 2.

\begin{tabular}{|c|c|c|c|c|c|}
\hline \multirow{2}{*}{ Tipo de estrutura } & \multirow{3}{*}{ Componente ou elemento } & \multicolumn{4}{|c|}{ Classe de agressividade ambiental } \\
\cline { 3 - 6 } & & I & II & III & IV \\
\cline { 3 - 6 } & & \multicolumn{4}{|c|}{ Cobrimento nominal (mm) } \\
\hline \multirow{2}{*}{ Concreto armado } & Laje & 20 & 25 & 35 & 45 \\
\cline { 3 - 6 } & Viga/Pilar & 30 & 35 & 40 & 50 \\
\hline Concreto protendido & Todos & 30 & 55 \\
\hline
\end{tabular}

Tabela 2 - Correspondência entre a classe de agressividade ambiental e a qualidade do concreto. Fonte: ABNT NBR $6118,2014$.

\subsection{Principais agentes de deterioração do concreto}

As causas químicas da degradação são agrupadas em três categorias:

a) hidrólise dos componentes da pasta do cimento por água pura;

b) trocas iônicas entre fluidos agressivos e a pasta do cimento;

c) reações causadoras de produtos expansíveis, tais como: na expansão por sulfatos, reação álcali-agregado e corrosão da armadura do concreto.

As causas físicas da deterioração do concreto podem ser agrupadas em duas categorias: desgaste superficial (perda de massa) devido à abrasão, erosão e cavitação; e fissuração devido a gradientes normais de temperatura e umidade, pressões de cristalização de sais nos poros, carregamento estrutural e exposição a extremos de temperatura tais como congelamento ou fogo (VILASBOAS, 2003).

\subsubsection{Causas químicas}

\subsubsection{Carbonatação}

Segundo Rivetti et al. (2018), a principal causa de corrosão em estruturas de concreto armado em meio urbano é o processo de carbonatação, no qual o dióxido de carbono $\left(\mathrm{CO}_{2}\right)$ penetra no concreto, reagindo com a água presente nos poros e formando ácido carbônico. O ácido carbônico reage com o portlandita $\left[\mathrm{Ca}(\mathrm{OH})_{2}\right]$, formado durante a hidratação do cimento, resultando na formação de carbonato de cálcio $\left(\mathrm{CaCO}_{3}\right)$. Esta reação causa uma redução do $\mathrm{pH}$ do ambiente, que leva ao inicio do processo de corrosão.

\subsubsection{Reação álcali-agregado}

A reação álcali-agregado gera um fenômeno expansivo no concreto. Apesar de existir três tipos de reações expansivas, álcali-sílica, álcali-silicato e álcali-carbonato, é de mais relevância a preocupação com a reação álcali-sílica. Esta reação somente acontecerá se houver a junção de sílica reativa, álcalis e água suficiente para gerar o gel expansivo, se o concreto permanecer seco, não ocorrerá (FUSCO, 2008).

\subsubsection{Ataque por cloretos e ação da água do mar}

A presença de cloretos no concreto, advindos da água do mar, da atmosfera marinha, de aditivos aceleradores de pega que contenham $\mathrm{CaCl}_{2}$, de água ou agregados contaminados ou de poluentes industriais, é uma das principais causas de corrosão das armaduras de concreto armado (ALMEIDA, SALES, 2014). Na presença de cloretos, o filme passivador pode ser destruído mesmo em valores de $\mathrm{pH}$ superiores a 11,5 e pequenas quantidades são necessárias para despassivar a armadura, relacionada com a quantidade de hidróxidos disponíveis nas soluções presentes nos poros do concreto (RIVETTI, et al., 2018). A presença dos cloretos traz à estrutura agentes ácidos que acabam por tornar um ambiente alcalino para a armadura em um ambiente ácido, estando condicionada a espessura do cobrimento nominal à concentração do dióxido de carbono no meio ambiente da edificação. 
A ação por da água do mar demanda uma atenção especial devido à complexidade de efeitos que ela pode causar nas estruturas de concreto. Além de ser nociva para a durabilidade das armaduras por aumentar a possibilidade de corrosão, também pode agir de forma direta sobre o concreto, causando simultaneamente processos químicos e físicos, tais como: ataque químico por parte dos sais dissolvidos, como cloretos e sulfatos, dilatação causada pela cristalização dos sais nos poros, erosão superficial provocada pelas ondas ou maré, entre outros. (RIBEIRO et al, 2014).

\subsubsection{Hidrólise dos componentes da pasta do cimento}

As águas puras (condensação de neblina, ou vapor) e águas moles (originadas da chuva ou da fusão de neve e gelo) podem conter pouco ou nenhum íon de cálcio. Quando estas águas entram em contato com a pasta de cimento, elas tendem a hidrolisar ou dissolver os produtos contendo cálcio. À medida que a solução de contato atinge o equilíbrio químico, a hidrólise adicional da pasta de cimento irá parar. Teoricamente, a hidrólise da pasta de cimento continua até que a maior parte do hidróxido de cálcio tenha sido retirada por lixiviação; isto expõe os outros constituintes do cimento à decomposição química. Dessa forma, o processo prejudica o gel de sílica e alumina, deixando-os com pouca ou nenhuma resistência (VILASBOAS, 2003).

Além da perda de resistência, a lixiviação do hidróxido de cálcio do concreto pode ser considerada indesejável por razões estéticas. Frequientemente, o produto lixiviado interage com o $\mathrm{CO}_{2}$ presente no ar e resulta na precipitação de crostas brancas de carbonato de cálcio na superfície. Este fenômeno, conhecido como eflorescência, é mais frequente nos concretos com porosidade nas proximidades da superfície e é influenciado pelo tipo de material das formas, o grau de adensamento e pela relação água/cimento. (VILASBOAS, 2003).

\subsubsection{Causas físicas}

Dentre as causas físicas, o desgaste superficial que á a perda progressiva de massa de uma superfície do concreto pode ocorrer devida à abrasão, erosão e cavitação. A abrasão ocorre quando há o atrito seco, como no caso do desgaste de pavimentos e pisos industriais pelo tráfego de veículo. A erosão é caracterizada quando ocorre o desgaste por ação abrasiva de fluidos contendo partículas sólidas em suspensão, como se observa em revestimentos de canais, vertedouros e tubulações para o transporte de água ou esgoto. Outra possibilidade de dano em estruturas hidráulicas é por cavitação, que se relaciona à perda de massa pela formação de bolhas de vapor e sua subseqüente ruptura devido a mudanças repentinas de direção em águas que fluem com alta velocidade. De maneira geral, a pasta de cimento endurecida não possui alta resistência ao atrito. A vida útil do concreto pode ser seriamente diminuída sob condições de ciclos repetidos de atrito, principalmente quando a pasta possui alta porosidade ou baixa resistência e é inadequadamente protegida por um agregado que não possui resistência ao desgaste (VILASBOAS, 2003).

Outras causas que podem ocasionar a fissuração são a sobrecarga, cristalização de sais nos poros e ação do gelo-degelo.

\subsection{Análise de degradação}

Existem estudos das manifestações patológicas em concreto armado buscando quantificar os danos existentes nas estruturas, conforme metodologia GDE/UnB. De acordo com Castro (1994), o método GDE/UnB tem o objetivo de fazer uma avaliação criteriosa de cada elemento e de toda a estrutura em si, quantificando a degradação. A metodologia quantifica o grau de dano, o grau de deterioração de um elemento, de uma família e da estrutura, conforme os itens seguintes.

\subsubsection{Grau de dano (D)}

O grau de dano (D) tem por objetivo quantificar a manifestação de cada dano no elemento, onde primeiramente os elementos estruturais são divididos em famílias e utilizando fatores de ponderação e de intensidade dos danos conseguimos calcular o valor de D. A classificação dessas famílias é definida como: famílias de pilares, vigas, lajes, cortinas, escadas e rampas, reservatório superior e inferior, blocos, juntas de dilatação e elementos arquitetônicos, podendo sofrer alterações de acordo com a particularidade de cada estrutura (CASTRO, 1994).

$\mathrm{O}$ fator de ponderação do dano (Fp) visa quantificar a importância relativa de um determinado dano, no que se refere às condições gerais de estética, funcionalidade e segurança dos elementos de uma família (CASTRO, 1994), expostos nas tabelas 3 a 6. 


\begin{tabular}{|c|c|}
\hline DANOS & $\mathrm{Fp}$ \\
\hline desvio de geometria & 8 \\
\hline recalque & 10 \\
\hline infiltração na base & 6 \\
\hline segregação & 6 \\
\hline lixiviação & 5 \\
\hline esfoliação & 8 \\
\hline desagregação & 7 \\
\hline sinais de esmagamento & 10 \\
\hline cobrimento deficiente & 6 \\
\hline manchas de corrosão & 7 \\
\hline fissuras & 10 \\
\hline carbonatação & 7 \\
\hline presença de cloretos & 10 \\
\hline manchas & 5 \\
\hline
\end{tabular}

Tabela 3: Fator de ponderação para pilares Fonte: CASTRO, 1994.

\begin{tabular}{|c|c|}
\hline DANOS & Fp \\
\hline segregação & 5 \\
\hline lixiviação & 3 \\
\hline esfoliação & 8 \\
\hline desagregação & 7 \\
\hline cobrimento deficiente & 6 \\
\hline manchas de corrosão & 7 \\
\hline flechas & 10 \\
\hline fissuras & 10 \\
\hline carbonatação & 7 \\
\hline infiltração & 6 \\
\hline presença de cloretos & 10 \\
\hline manchas & 5 \\
\hline
\end{tabular}

Tabela 5: Fator de ponderação para lajes Fonte: CASTRO, 1994.

\begin{tabular}{|c|c|}
\hline DANOS & $\mathrm{Fp}$ \\
\hline Segregação & 4 \\
\hline Lixiviação & 5 \\
\hline Esfoliação & 8 \\
\hline Desagregação & 7 \\
\hline Cobrimento deficiente & 6 \\
\hline Manchas de corrosão & 7 \\
\hline Flechas & 10 \\
\hline Fissuras & 10 \\
\hline Carbonatação & 7 \\
\hline Infiltração & 6 \\
\hline Presença de cloretos & 10 \\
\hline Manchas & 5 \\
\hline
\end{tabular}

Tabela 4: Fator de ponderação para vigas Fonte: CASTRO, 1994.

\begin{tabular}{|c|c|}
\hline DANOS & Fp \\
\hline segregação & 5 \\
\hline lixiviação & 3 \\
\hline esfoliação & 8 \\
\hline Desagregação & 7 \\
\hline cobrimento deficiente & 6 \\
\hline manchas de corrosão & 7 \\
\hline flechas & 10 \\
\hline fissuras & 10 \\
\hline carbonatação & 7 \\
\hline infiltração & 6 \\
\hline presença de cloretos & 10 \\
\hline manchas & 5 \\
\hline
\end{tabular}

Tabela 6: Fator de ponderação para rampas Fonte: CASTRO, 1994.

Segundo Castro,1994 o fator de intensidade do dano (Fi) classifica o nível de gravidade e a evolução de uma manifestação de dano em um determinado elemento, segundo uma escala de 0 a 4, na forma proposta por Ribeiro, 2014 como mostra a tabela 7 .

\begin{tabular}{|c|c|}
\hline \multicolumn{2}{|c|}{ Fator de intensidade } \\
\hline Sem lesões & $\mathrm{Fi}=0$ \\
\hline Lesões leves & $\mathrm{Fi}=1$ \\
\hline Lesões toleráveis & $\mathrm{Fi}=2$ \\
\hline Lesões graves & $\mathrm{Fi}=3$ \\
\hline Estado crítico & $\mathrm{Fi}=4$ \\
\hline
\end{tabular}

Tabela 7: Fator de intensidade Fonte: CASTRO, 1994.

Caso o Fp for $=10$, o grau de deterioração é calculado pelas seguintes expressões: 


$$
\begin{aligned}
& \mathrm{D}=4 \times \mathrm{Fi} \text { para } \mathrm{Fi} \leq 2,0 \\
& \mathrm{D}=60 \times \mathrm{Fi}-140 \text { para } \mathrm{Fi} \geq 3,0
\end{aligned}
$$

No caso de $\mathrm{Fp}<10$ as expressões são multiplicadas por Fp/10:

$$
\begin{gathered}
D=0,4 F i \times F p \\
D=(6 \times G i-14) \times F p
\end{gathered}
$$

$\mathrm{Fi}=$ Fator de intensidade;

$\mathrm{Fp}=$ Fator de ponderação.

\subsubsection{Grau de deterioração de um elemento (Gde)}

Após determinado os graus de danos (D), calcula-se o Grau de deterioração do elemento (Gde), que é determinado conforme as expressões dadas a seguir:

$$
\begin{gathered}
\text { Dmáx para } \mathrm{m} \leq 2,0 \\
\text { Gde }=\text { Dmáx }+\sum \mathrm{Di} /(\mathrm{m}-1) \text { para } \mathrm{m}>2,0
\end{gathered}
$$

Onde:

$\mathrm{D}=$ Grau do dano de ordem (i);

$\mathrm{m}=$ Número de danos detectados no elemento.

Segundo Castro (1994) é também conveniente estabelecer uma escala de medidas necessárias a se tomar com relação a um elemento, com base no seu grau de deterioração, Gde, calculado a partir de todos os danos nele detectados. Dessa forma, baseando-se na aplicação e ajuste da metodologia a situações reais, elaborou-se a Tabela 8, com recomendações para elementos isolados. Deve-se observar que os limites estabelecidos não devem ser encarados como absolutos, mas como indicativos das medidas a se adotar. Como mostrado na tabela 8 :

\begin{tabular}{|c|c|c|}
\hline Nível de deterioração & Gde & Medidas a serem adotadas \\
\hline Baixo & $0-15$ & Estado aceitável \\
\hline Médio & $15-50$ & observação periódica e necessidade de intervenção em médio prazo \\
\hline Alto & $50-80$ & observação periódica minuciosa e necessidade de intervenção em curto \\
prazo
\end{tabular}

Tabela 8: Classificação dos níveis de deterioração.

Fonte: CASTRO, 1994.

\subsubsection{Grau de deterioração de uma família (Gdf)}

Segundo Castro (1994) é definida como a média aritmética dos graus de deterioração dos “n” elementos com danos expressivos, de forma a evidenciar os elementos em pior situação. Para danos expressivos estabelecem-se o limite Gde $\geq 15$, obtendo-se:

$$
\operatorname{Gdf}=\operatorname{Gde}(\mathrm{i}) / \mathrm{n}
$$

Onde:

$\mathrm{n}=$ número de elementos componentes da família com Gde $\geq 15$ 
Quando em uma família de elementos verificarem-se graus de deterioração Gde < 15 para todos os elementos, o grau de deterioração da família será Gdf = 0, não contribuindo para o cálculo do grau de deterioração da estrutura (CASTRO, 1994).

\subsubsection{Grau de deterioração da estrutura $(\mathrm{Gd})$}

Calculado pela média ponderada dos graus de deterioração das diversas famílias de elementos, tendo como peso o fator de relevância estrutural "Fr". Expresso na tabela 9:

\begin{tabular}{|l|l|}
\hline - Elementos de composição arquitetônica: & $\mathrm{Fr}=1,0$ \\
\hline - Reservatório superior: & $\mathrm{Fr}=2,0$ \\
\hline - Escadas/Rampas, Reservatório inferior, Cortinas, Lajes secundárias: & $\mathrm{Fr}=3,0$ \\
\hline - Lajes, fundações, Vigas secundárias, Pilares secundários: & $\mathrm{Fr}=4,0$ \\
\hline - Vigas e Pilares principais & $\mathrm{Fr}=5,0$ \\
\hline
\end{tabular}

Tabela 9: Fator de relevância estrutural das famílias de elementos.

Fonte: CASTRO,1994.

$$
\operatorname{Gd}=\sum \operatorname{Fr}(i) \times \operatorname{Gdf}(i) / \sum \operatorname{Fr}(\mathrm{i})
$$

Onde:

Fr = Fator de relevância estrutural de cada família;

Gdf = Grau de deterioração da família.

\begin{tabular}{|c|c|c|}
\hline $\begin{array}{c}\text { Nível de } \\
\text { deterioração }\end{array}$ & Gd & Medidas a serem adotadas \\
\hline Baixo & $0-15$ & estado aceitável \\
\hline Médio & $15-40$ & observação periódica e necessidade de intervenção em médio prazo \\
\hline Alto & $40-60$ & observação periódica minuciosa e necessidade de intervenção em curto prazo \\
\hline Crítico & $>60$ & necessidade de intervenção imediata para restabelecer funcionalidade e/ou segurança \\
\hline
\end{tabular}

Tabela 10: Classificação dos níveis de deterioração da estrutura.

Fonte: CASTRO, 1994.

Calculado o valor de Gd, classifica-se a estrutura em um dos quatro níveis de deterioração, que indica as ações a serem tomadas. Cabe destacar a importância da análise estrutural individual dos elementos, pois pode ser recomendada a intervenção imediata ou em curto prazo apenas em elementos isolados da estrutura, dependendo do fator de intensidade de um dano ou do grau de deterioração do elemento (CASTRO,1994).

\section{METODOLOGIA}

O estudo desenvolvido analisou a degradação da garagem G1, G2 e G3 de um edifício de 15 pavimentos, construído em 2008, localizado no bairro do Stiep em Salvador no estado da Bahia. No dia 15/11/2019 foi feita uma inspeção no condomínio para a análise das manifestações patológicas existentes. As etapas desenvolvidas estão expostas a seguir:

- $1^{\text {o }}$ etapa: Primeiramente realizou-se uma visita técnica ao local escolhido para o estudo e analisar todo um sistema, destacando os elementos com anomalias. Esta etapa poderia ter sido realizada através do projeto da edificação, o que daria uma visão mais clara da real distribuição estrutural, porém, pela falta de acesso aos projetos não foi possível fazer essa análise prévia.

- $\quad 2^{\circ}$ etapa: Com o caderno de inspeções indicado por Castro (1994), avaliou-se visualmente cada elemento estrutural e suas manifestações patológicas, dividindo-os em famílias e podendo assim determinar um Fator de intensidade (Fi) e Fator de ponderação (Fp) para cada uma delas.

- $\quad 3^{\circ}$ etapa: Com a observação das manifestações patológicas, desenvolveu-se os cálculos necessários para a avaliação tanto da estrutura, quanto de cada elemento estrutural. 
Nesta análise não poderemos quantificar de forma precisa as manifestações patológicas como a carbonatação, presença de cloretos e recalque, pois para avaliar essas manifestações patológicas seriam necessários ensaios específicos. Porém, é possível fazer uma avaliação visual das outras manifestações patológicas. Abaixo segue o fluxograma com esquema das etapas desenvolvidas.

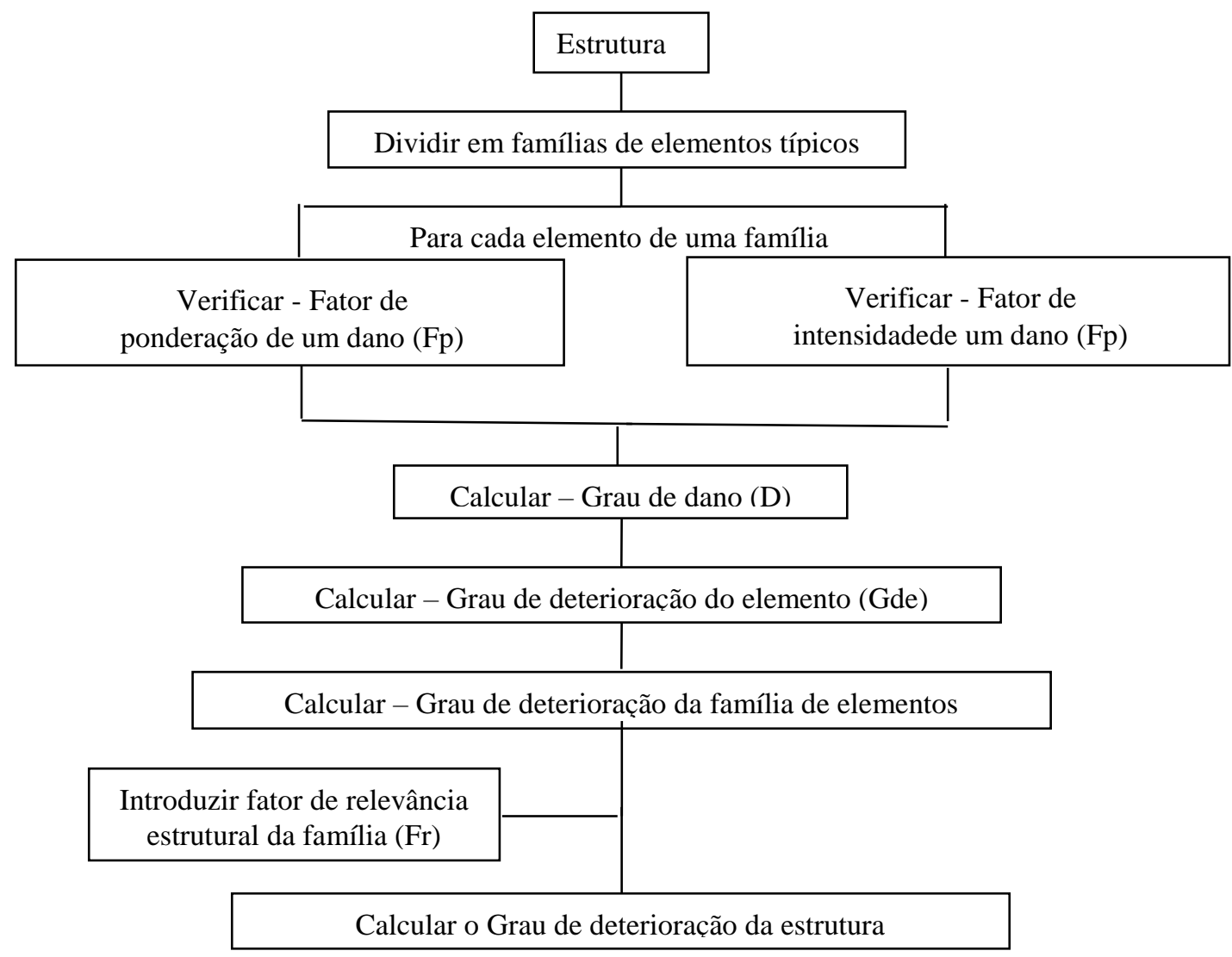

4.

\section{RESULTADOS}

Durante a visita técnica, observou-se que a área mais degradada é a laje de uma área aberta, na qual recentemente passou por reforma do piso. Segundo depoimento de moradores, os problemas surgiram após a reforma desta área, visto que houve a troca de piso e contrapiso em uma área que possui uma manta asfáltica. Durante a reforma houve dano a manta que impermeabilizava a área, desta forma, a água começou a percolar pelo concreto atingindo a garagem e causando diversas manifestações patológicas. Destaca-se que diante da vistoria não foi encontrado nenhum problema nos pilares, sendo assim, nosso estudo estará focado nas famílias de lajes, vigas e rampas das garagens.

\subsection{Família de lajes}

Em um trecho da laje do G1 onde não há cobertura foi constatada infiltrações com Fi = 3 (lesões graves) e manchas com $\mathrm{Fi}=4$ (estado crítico). Já no pavimento G2 foram observados problemas de fissuras com $\mathrm{Fi}=1$ (lesões leves) que junto a infiltração classificada com $\mathrm{Fi}=3$ causada por uma execução inadequada da reforma, que ocasionou a um alto grau de aparecimento de eflorescências com $\mathrm{Fi}=3$ e pequenas manchas, $\mathrm{Fi}=1$. No G3 não foram constatadas manifestações patológicas nas lajes.

As tabelas a seguir trazem os resultados do grau de Dano (D) com o $F p \leq 10$ e $F p=10$. As equações usadas são: (1), (2), (3) e (4), dependendo do grau de Fi para cada patologia observada. A partir dos valores de D é possível calcular o Grau de deterioração do elemento (Gde), levando em conta o número de danos atuantes (m), pelas Equações (5) e (6). Resultados expressos nas tabelas 11 e 12: 


\begin{tabular}{|c|c|c|c|}
\hline Nome do Elemento & \multicolumn{3}{|c|}{ Laje } \\
\hline Local & \multicolumn{3}{|c|}{ G1 } \\
\hline Danos & Fp & Fi & D \\
\hline infiltrações & 6 & 3 & 24 \\
\hline manchas & 5 & 4 & 50 \\
\hline & \multicolumn{4}{|c|}{ Gde } & 50 \\
\hline
\end{tabular}

Tabela 11: Resultados de (D) e do grau de deterioração do elemento (Gde) na laje do pav. G1. FONTE: Autor (2019)

\begin{tabular}{|c|c|c|c|}
\hline Nome do Elemento & \multicolumn{3}{|c|}{ Laje } \\
\hline Local & \multicolumn{3}{|c|}{ G2 } \\
\hline Danos & $\mathrm{Fp}$ & $\mathrm{Fi}$ & $\mathrm{D}$ \\
\hline eflorescência & 3 & 3 & 12 \\
\hline fissuras & 10 & 1 & 4 \\
\hline infiltrações & 6 & 3 & 24 \\
\hline manchas & 5 & 1 & 2 \\
\hline & \multicolumn{2}{|c|}{ Gde } & 30 \\
\hline
\end{tabular}

Tabela12: Resultados de (D) e do grau de deterioração do elemento (Gde) na laje do pav. G2. FONTE: Autor (2019)

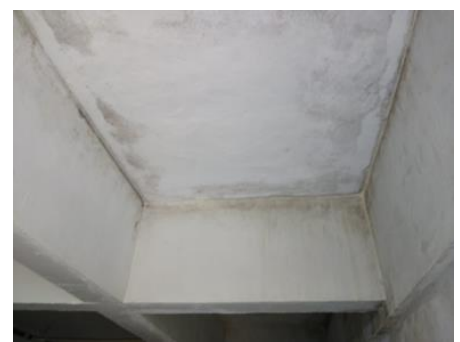

Imagem 1: Infiltração e manchas de umidade na laje do pav. G1. FONTE: Autor 2019

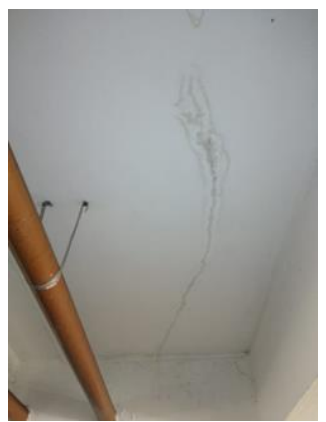

Imagem 2 Fissura, infiltração e manchas de umidade na laje do pav. G2.

FONTE: Autor, 2019

Podemos concluir que no pavimento G1 o nível de deterioração é alto, cabendo perícias minuciosas e periódicas e intervenção em curto prazo. No G2 existe um nível de deterioração médio, cabendo observações periódicas e intervenção em médio prazo.

\subsection{Família de vigas}

Utilizando os mesmos princípios do ítem 2.4.1, calculou-se para as vigas o Grau de dano (D) e o Grau de deterioração do elemento (Gde). Cujo resumo consta na tabela 13:

\begin{tabular}{|c|c|c|c|}
\hline Nome do Elemento & \multicolumn{3}{|c|}{ Viga } \\
\hline Local & \multicolumn{3}{|c|}{ G1 } \\
\hline Dano & Fp & Fi & D \\
\hline infiltração & 6 & 3 & 24 \\
\hline manchas & 5 & 4 & 50 \\
\hline & & Gde & 50 \\
\hline
\end{tabular}

Tabela 13: Resultados de (D) e do grau de deterioração do elemento (Gde) nas vigas do pav. G1. FONTE: Autor, 2019

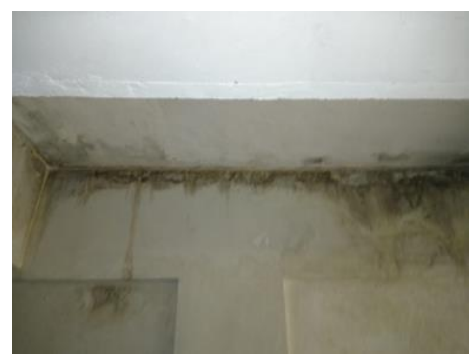

Imagem 3: Infiltração e manchas de umidade em uma viga do pav. G1. FONTE: Autor, 2019 


\begin{tabular}{|c|c|c|c|}
\hline Nome do Elemento & \multicolumn{3}{|c|}{ Viga } \\
\hline Local & \multicolumn{3}{|c|}{ G2 } \\
\hline Dano & Fp & Fi & D \\
\hline eflorescência & 5 & 4 & 50 \\
\hline manchas de corrosão & 7 & 3 & 28 \\
\hline infiltração & 6 & 4 & 60 \\
\hline manchas & 5 & 4 & 50 \\
\hline & & Gde & 102,6667 \\
\hline
\end{tabular}

Tabela 14: Resultados de (D) e do grau de deterioração do elemento (Gde) nas vigas do pav. G2.

FONTE: Autor. 2019

\begin{tabular}{|c|c|c|c|}
\hline Nome do Elemento & \multicolumn{4}{|c|}{ Viga } \\
\hline Local & \multicolumn{3}{|c|}{ G3 } \\
\hline Dano & Fp & Fi & D \\
\hline eflorescência & 5 & 3 & 20 \\
\hline desagregação & 7 & 2 & 5,6 \\
\hline cobrimento deficiente & 6 & 3 & 24 \\
\hline manchas de corrosão & 7 & 4 & 70 \\
\hline fissuras & 10 & 3 & 40 \\
\hline carbonatação & 7 & 3 & 28 \\
\hline infiltração & 6 & 3 & 24 \\
\hline manchas & 5 & 3 & 20 \\
\hline & & Gde & 93,08571 \\
\hline
\end{tabular}

Tabela 15: Resultados de (D) e do grau de deterioração do elemento (Gde) nas vigas do pav. G3. FONTE: Autor (2019).

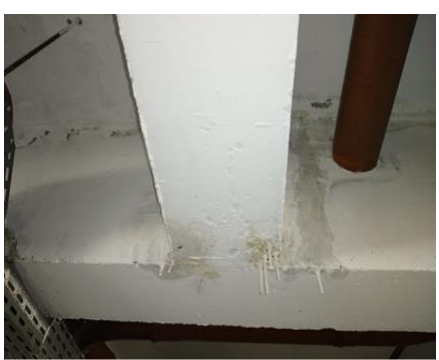

Imagem 5: Eflorescência em viga do pav. G2. FONTE: Autor, 2019

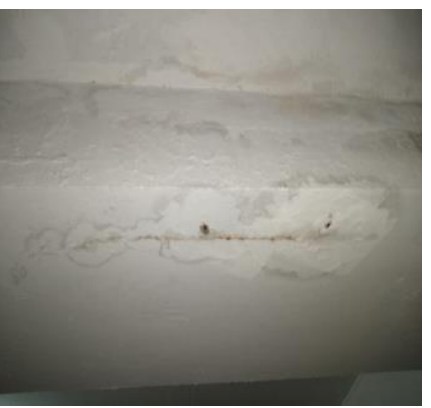

Imagem 7: Manchas de corrosão e umidade, cobrimento deficiente, carbonatação, eflorescência e desagregação em viga no pav. G3. FONTE: Autor, 2019.

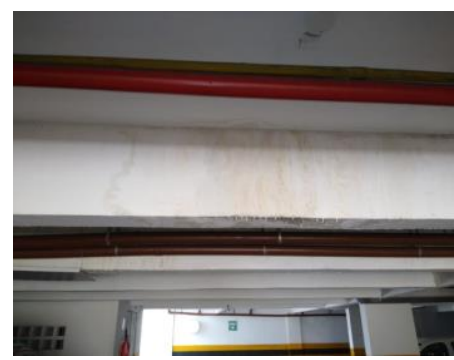

Imagem 6: Manchas de corrosão e eflorescência. FONTE: Autor,

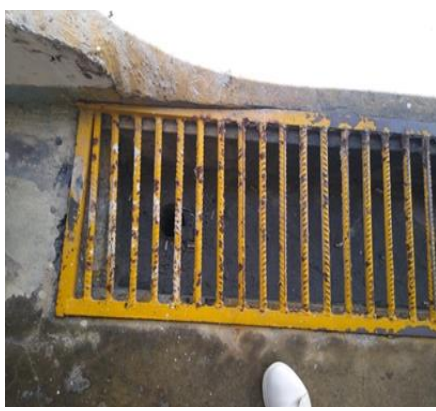

Imagem 8: Ralo situado acima da viga mostrada na imagem 7, possível potencializadora de tantas manifestações patológicas. FONTE: Autor, 2019

Nas vigas se encontraram mais manifestações patológicas que nas lajes. Conclui-se que no pavimento G1, assim como nas lajes, o nível de deterioração é alto, cabendo perícias minuciosas e periódicas e intervenção em curto prazo. No G2 observou-se um estado crítico, com altos níveis de eflorescência, manchas de corrosão, infiltração e manchas de umidade, o que levou a esse estado foi justamente a reforma mal feita, onde como já foi observado, houve dano à manta de impermeabilização, com a necessidade de intervenção imediata. No pavimento G3 verificou-se danos apenas em um viga, ao analisar a causa desta viga apresentar manifestações patológicas, constatou-se que está situada exatamente embaixo de um ralo do pavimento superior, sendo assim, possivelmente á agua do ralo está infiltrando na viga e desencadeando diversos outros problemas. Esta viga necessita de intervenção imediata, pois seu estado é crítico.

\subsection{Família de Rampas}

Com a mesma metodologia usada nos itens 2.4.1 e 2.4.2, determinou-se o grau de degradação para as rampas, o Grau de dano (D) e o Grau de deterioração do elemento (Gde). 


\section{CBPAT 2020 \\ CONGRESSO BRASILEIRO DE PATOLOGIA DAS CONSTRUÇÕES \\ DE 15 A 17 DE ABRIL | FORTALEZA - CE}

\begin{tabular}{|c|c|c|c|}
\hline Nome do Elemento & \multicolumn{4}{|c|}{ Rampa } \\
\hline Local & \multicolumn{3}{|c|}{ G1/G2 e G2/G3 } \\
\hline Dano & $\mathrm{FP}$ & $\mathrm{Fi}$ & $\mathrm{D}$ \\
\hline desagregação & 7 & 3 & 28 \\
\hline cobrimento deficiente & 6 & 3 & 24 \\
\hline manchas de corrosão & 7 & 3 & 28 \\
\hline fissuras & 10 & 3 & 40 \\
\hline carbonatação & 7 & 3 & 28 \\
\hline infiltração & 6 & 2 & 4,8 \\
\hline manchas & 5 & 2 & 4 \\
\hline & & Gde & 59,46667 \\
\hline
\end{tabular}

Tabela 16: Resultados de (D) e do grau de deterioração do elemento (Gde) nas rampas de G2 para G3.

FONTE: Autor (2019).

Nas Rampas na rampa G1/G2 e G2/G3 foram identificadas diversas manifestações patológicas semelhantes. Por exemplo, a carbonatação nos pontos que sofreram com a desagregação e com o cobrimento inadequado do concreto, além de manchas de corrosão, fissuras, infiltração e manchas de infiltração. Foi atribuído um nível de risco alto, sendo necessárias vistorias detalhadas e periódicas, além de medidas em curto prazo.

\subsection{Grau de deterioração das famílias}

Com os valores dos graus de deterioração dos elementos calculados e com o auxílio da equação 7 poderemos calcular o grau de deterioração das famílias:

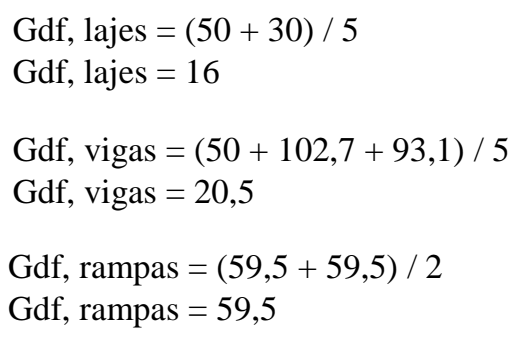

\subsection{Grau de deterioração da estrutura (Gd)}

Após calculado o grau de deterioração da família atribuiu-se um fator de relevância para cada elemento de estudo, estes fatores estão explícitos na tabela 9. Sendo assim, pode-se determinar o Grau de deterioração da estrutura (Gd) usando a equação 8, apresentando o seguinte valor, conforme exposto a seguir:

$$
\begin{aligned}
& \mathrm{Gd}=[(3+4+5) \times(59,5+20,5+16)] /(3+4+5) \\
& \mathrm{Gd}=96
\end{aligned}
$$

O resultado comprado aos limites para as classificações de riscos globais da estrutura, permite concluir que que o estado da estrutura como um todo é crítica e são necessárias medidas imediatas.

\section{CONCLUSÃO}

A metodologia GDE/UnB permite quantificar quais são os elementos que necessitam de mais prioridade, classificando inclusive a situação da edificação e dos seus elementos. Este método é importante para tomadas de providências, indicando a prioridade das intervenções necessárias nos elementos estruturais. De acordo com a análise realizada, os elementos estruturais que precisam ser recuperados com maior urgência são: as lajes e vigas do pavimento G1, que 
apresentam risco alto; as rampas que ligam G1 à G2 e G2 à G3, que apresentam risco alto; as vigas do pavimento G2, que estão no estado crítico e a viga de do pavimento G3, também no estado crítico.

O desenvolvimento do trabalho permitiu analisar a importância de identificar e quantificar as manifestações patológicas, de forma a priorizar as intervenções mais minuciosas. Observa-se que apesar de determinadas manifestações patológicas pareçam insignificantes, acabam desencadeando outras várias manifestações que geralmente agravam a situação das estruturas, comprometendo seu desempenho e reduzindo sua vida útil.

Como recomendação para novos trabalhos fica o estudo em relação ao fator de intensidade que é totalmente dependente da análise as vezes visual do especialista, causando uma margem de erro de pessoa para pessoa que faz a inspeção. A criação de um método com parâmetros mais bem estabelecidos dará mais segurando e embasamento à este método.

6. REFERÊNCIAS

ABNT NBR 6118/2014. Projeto de estruturas de concreto - Procedimento.

ALMEIDA F.C.R., SALES A. Efeitos da ação do meio ambiente sobre as estruturas de concreto. In: Ribeiro DV, editor. Corrosão em Estruturas de Concreto Armado: Teoria, Controle e Métodos de Análise. 1st ed. Rio de Janeiro: Elsevier; 2014. p. 51-73.

BAROGHEL-BOUNY, V.; CAPRA, B.; LAURENS, S. A durabilidade das armaduras e do concreto de cobrimento. Durabilidade do Concreto - Bases científicas para a formulação de concretos duráveis de acordo com o ambiente. $1^{\mathrm{a}}$ Edição - Editora IBRACON. São Paulo, 2014.

CASTRO, Eliane. Desenvolvimento de Metodologia para Manutenção de Estruturas de Concreto Armado, Universidade de Brasília, 1994.

FIGUEIREDO e MEIRA. Corrosão das armaduras das estruturas de concreto, BOLETIM TÉCNICO, ALCONPAT BRASIL, 2013.

FUSCO, Péricles. Tecnologia do Concreto Estrutural, $1^{\circ}$ EDIÇÃO, $1^{\circ}$ TIRAGEM, Ed. PINI Ltda, São Paulo, 2008.

CARVAlHO e FILHO. Cálculo e Detalhamento de Estruturas Usuais de Concreto Armado, $4^{\mathrm{a}}$ EDIÇÃO, Ed. EdUFSCar. São Carlos, 2014.

RIBEIRO, SALES, SOUSA, ALMEIDA, CUNHA, LOURENÇO, HELENE. Corrosão em Estruturas de Concreto

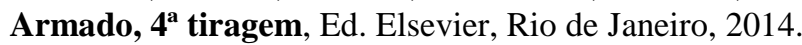

RIVETTI Et al. Corrosion Inhibitors for Reinforced Concrete, 2018.

SILVA, Sarah. Diagnóstico de Estruturas de Concreto em Ambientes Marinhos: Estudo de Caso de uma Plataforma de Pesca. Universidade Federal de Goiás, 2017.

VILASBOAS, José. Durabilidade das edificações de concreto armado em Salvador: uma contribuição para a implantação da NBR 6118: 2003. UFBA, Departamento de Engenharia Ambiental - DEA. 